\title{
Uma nova espécie de Ocotea (Lauraceae) para o Brasil
}

A new species of Ocotea (Lauraceae) from Brazil

\author{
Marcelo Leandro Brotto ${ }^{1}$, João Batista Baitello ${ }^{2}$, \\ Armando Carlos Cervi ${ }^{1}$ \& Élide Pereira dos Santos ${ }^{1,3}$
}

\begin{abstract}
Resumo
Uma nova espécie de Ocotea Aubl. (Lauraceae), Ocotea paranaensis Brotto, Baitello, Cervi \& E.P.Santos, é descrita e ilustrada, baseado na revisão das Lauraceae que ocorrem na Floresta Atlântica no estado do Paraná, no sul do Brasil.

Palavras-chave: Floresta Atlântica, Ocotea paranaensis, Paraná, Serra do Mar, taxonomia.
\end{abstract}

\begin{abstract}
A new species of Ocotea Aubl. (Lauraceae), Ocotea paranaensis Brotto, Baitello, Cervi \& E.P.Santos, is described and illustrated based on a recent revision of Lauraceae from the Atlantic Forest Paraná state, southern Brazil.
\end{abstract}

Key words: Atlantic Forest, Ocotea paranaensis, Paraná, Serra do Mar, taxonomy.

\section{Introdução}

O gênero Ocotea Aubl., com aproximadamente 350 espécies, é o maior gênero de Lauraceae nos Neotrópicos. No Brasil, Ocotea está representado por cerca de 160 espécies, enquanto aproximadamente 50 espécies ocorrem em Madagáscar, sete na África e uma nas Ilhas Canárias (Rohwer 1993; Baitello 2001). É um gênero muito diverso e caracterizado por apresentar estames com os locelos (sacos polínicos) em pares sobrepostos, em geral sem papilas nas anteras, e flores diclinas a monoclinas.

Algumas espécies de Ocotea apresentam madeira de boa qualidade, razão pela qual foram amplamente exploradas durante séculos. Esta exploração resultou na inclusão de seis espécies do gênero na lista oficial das espécies da flora brasileira ameaçadas de extinção, três das quais com ocorrência na Floresta Atlântica do Paraná (MMA 2008).

Originalmente a Floresta Atlântica distribuíase ao longo de uma faixa costeira de largura variável, estendendo-se do estado do Rio Grande do Norte até o Rio Grande do Sul, e cobrindo cerca de $15 \%$ do território brasileiro. Os remanescentes mais bem conservados estão no leste do Paraná, sudeste de
São Paulo e Rio de Janeiro, principalmente sobre a Serra do Mar, que é um conjunto de escarpas com cerca de $1.000 \mathrm{~km}$ de extensão, estendendo-se do Rio de Janeiro ao norte de Santa Catarina (Almeida \& Carneiro 1998). A dificuldade de acesso a essa região, em geral escarpada, favorece a conservação dos remanescentes, onde hoje são desenvolvidos estudos intensivos sobre sua biodiversidade, o que tem levado à descoberta de novas espécies e novas ocorrências.

Nos últimos dez anos, seis novas espécies de Ocotea foram descritas a partir de coletas realizadas na Floresta Atlântica: Ocotea calliscypha L.C.S.Assis \& Mello-Silva, O. ciliata L.C.S.Assis \& Mello-Silva, O. cryptocarpa Baitello, $O$. curucutuensis Baitello, O. marcescens L.C.S.Assis \& Mello-Silva e O. pluridomatiata A.Quinet (Baitello 2001; Quinet 2008; Assis \& Mello-Silva 2009).

Durante o estudo taxonômico de Lauraceae ocorrentes na Floresta Atlântica no estado do Paraná (Brotto et al. 2009), foram coletadas amostras e analisadas as coleções de Ocotea disponíveis nos herbários do sudeste e sul do Brasil, que culminou na identificação de uma espécie nova, que é descrita no presente trabalho.

\footnotetext{
Universidade Federal do Paraná, Setor de Ciências Biológicas, Depto. Botânica, C.P. 19031, 81531-970, Curitiba, PR, Brasil.

${ }^{2}$ Instituto Florestal, R. do Horto 931, 02377-000, Horto Florestal, São Paulo, SP, Brasil.

${ }^{3}$ Autor para correspondência: elide@ufpr.br
} 


\section{Material e Métodos}

Este estudo foi realizado através da análise das coleções depositadas nos herbários ESA, MBM, MO, RB, SPSF e UPCB (Thiers 2009, continuamente atualizado) e HFIE (Herbário das Faculdades Integradas Espíritas, Curitiba, PR). O estado de conservação da espécie seguiu os critérios da IUCN versão 3.1 (2001).

\section{Resultados e Discussão}

Ocotea paranaensis Brotto, Baitello, Cervi \& E.P.Santos, sp. nov. Tipo: BRASIL. PARANÁ: Guaratuba, Serra de Araçatuba, Morro dos Perdidos, 2552'73'S, 4858'24'W, 7.V.2007, fl.Q, E.P. Santos \& M.L. Brotto 1184 (holótipo UPCB!; isótipos MBM!, RB!, SPSF!).

Fig. 1

Species haec ab Ocotea lancifolia (Schott)

Mez foliis apice acuminatis (non acutis), nervis secundariis 4-6-jugis (non 6-10-jugis), floribus tomentosis (non puberulis vel glabris) et fructibus globosis (non ellipsoideis) differt.

Árvore dióica, até ca. $14 \mathrm{~m}$ alt. Folhas alternas; pecíolo 4-10 mm compr., subcanaliculado, tomentoso; lâmina 4-8 $\times 1-2 \mathrm{~cm}$, lanceolada a estreitamente elíptica, glabra, discolor, ápice acuminado, base cuneada, face adaxial com reticulação densa, inconspícua, de cor mais clara que o limbo, nervuras impressas, face abaxial com reticulação densa, conspícua, de cor semelhante ao limbo, nervuras salientes, as secundárias 4-6 pares, ângulo de divergência da nervura principal $20^{\circ}-60^{\circ}$, padrão de nervação broquidódromo, domácias ausentes. Inflorescências axilares e subterminais, panículas 4-7 cm compr., com 9-18 flores, áureo-tomentosas. Flores diclinas, tomentosas; flores estaminadas ca. 4 mm de diâm.; pedicelo ca. $2 \mathrm{~mm}$ compr.; hipanto inconspícuo; tépalas 1,9-2,2 mm compr., elípticas, reflexas, subiguais em tamanho; estames das séries I e II ca. 2,3 mm compr., filetes tão longos quanto as anteras, tomentosos, anteras ovalado-retangulares, ápice obtuso, locelos introrsos; estames da série III ca. 2,3 mm compr., filetes tão longos quanto as anteras, tomentosos, glândulas inseridas na base, anteras ovalado-retangulares, ápice obtuso, locelos superiores lateral-introrsos e inferiores lateralextrorsos; estaminódios da série IV ca. 0,7 mm compr., filiformes, tomentosos; pistilóide ca. 2,8 mm compr., estipiforme, tomentoso; flores pistiladas ca. $5 \mathrm{~mm}$ diâm.; pedicelo ca. $2 \mathrm{~mm}$ compr.; hipanto inconspícuo; tépalas ca. 4 mm compr., ovaladas, reflexas, iguais; estaminódios 1,3-1,5 mm compr.; pistilo ca. 3,5 mm compr., ovário globoso, glabro, estilete tão longo quanto o ovário, tomentoso, estigma capitado. Fruto ca. $15 \times 15 \mathrm{~mm}$, globoso, cúpula ca. $7 \times 5 \mathrm{~mm}$, sub-hemisférica, margem simples. Material examinado: BRASIL. PARANÁ: Tijucas do Sul, 27.III.1990, fl.o", J.M. Silva \& G. Hatschbach 838 (ESA, MBM, MO); Tunas do Paraná, Pacas, 23.III.2001, fl.ơ, J.M. Silva et al. 3357 (MBM, MO, RB); São José dos Pinhais, Cunhãy, 10.I.2004, fr., A. Dunaiski Jr. 2230 (HFIE, UPCB); Guaratuba, Serra de Araçatuba, Morro dos Perdidos, 2552'73"S, 48 58'24"W, 25.IX.2007, fr., M.L. Brotto \& D.A. Brotto 39 (MBM, UPCB).

Ocotea paranaensis ocorre em Floresta Atlântica, no leste do estado do Paraná, em áreas montanhosas da Serra do Mar, entre 850 a 975 m. Coletada com flores de março a junho e com frutos de julho a janeiro. O epíteto específico faz alusão ao estado do Paraná, único local onde a espécie foi até o momento coletada.

De acordo com os critérios da IUCN (2001), Ocotea paranaensis pode ser considerada Em Perigo (B1ab(iii)). Os dois pontos mais distantes entre si, onde a espécie foi coletada, distam aproximadamente $120 \mathrm{~km}$, e apesar de ainda não ter sido encontrada em área protegida existem várias Unidades de Conservação ao longo dessa faixa. Aparentemente, a espécie ocorre em agrupamento de indivíduos como observado no local do holótipo.

Ocotea paranaensis assemelha-se vegetativamente à $O$. lancifolia (Schott) Mez, $O$. pulchella (Nees) Mez e O. bicolor Vattimo-Gil. As flores de $O$. paranaensis assemelham-se mais às de $O$. lancifolia, no entanto esta última ocorre em remanescentes de Savana (domínio do Cerrado), no norte do estado do Paraná, enquanto que $O$. paranaensis é encontrada em áreas de Floresta Ombrófila Densa (domínio da Mata Atlântica), no leste do estado. A característica que melhor diferencia as três espécies de $O$. paranaensis é o fruto globoso, com cerca de $1,5 \mathrm{~cm}$ de diâmetro, enquanto que as outras apresentam frutos menores e de outras formas. A Tabela 1 mostra a variabilidade dos caracteres diagnósticos entre essas espécies.

A espécie, por suas características vegetativas, assemelha-se àquelas do subgrupo Ocotea lancifolia (Schott) Mez, do complexo O. floribunda (Sw.) Mez, conforme Rohwer (1986). Segundo este autor, o complexo $O$. floribunda tem características morfológicas muito variáveis no comprimento, forma e indumento da lâmina foliar. As flores apresentam 


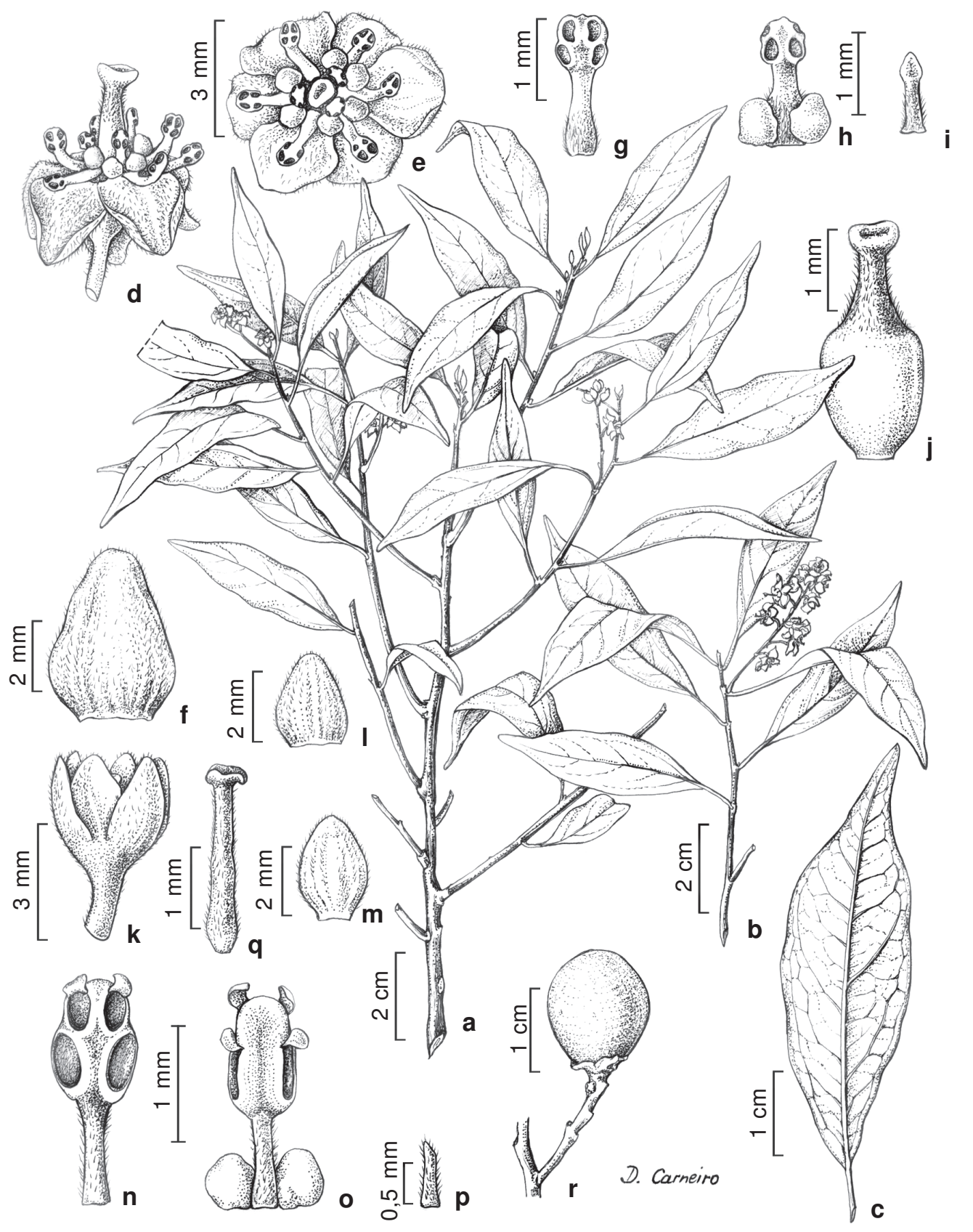

Figura 1 - Ocotea paranaensis - a-b. ramos floríferos; c. face abaxial da folha; d. flor f, vista lateral; e. flor f, vista frontal; f. face abaxial da tépala; g. face adaxial do estaminódio da série I; h. face abaxial do estaminódio da série III; i. estaminódio da série IV; j. pistilo; k. flor M; 1 . face abaxial da tépala da série I; m. face abaxial da tépala da série II; n. face adaxial do estame da série I; o. face abaxial do estame da série III; p. estaminódio da série IV; q. pistilódio; r. fruto (a-j Santos \& Brotto 1184; k-q Silva \& Hatschbach 838; r Dunaiski Jr. 2230).

Figure 1 - Ocotea paranaensis - a-b. flowering branches; c. abaxial leaf surface; d. flower F, lateral view; e. flower F, frontal view; f. abaxial tepal surface; g. adaxial staminode surface series I; h. abaxial staminode surface series III; i. staminode series IV; j. pistil; k. flower M; 1. abaxial tepal surface series I; m. abaxial tepal surface series II; n. adaxial stamen surface series I; o. abaxial stamen surface series III; p. staminode series IV; q. pistillode; r. fruit (a-j Santos \& Brotto 1184; k-q Silva \& Hatschbach 838; r Dunaiski Jr. 2230). 
Tabela 1 - Comparação morfológica entre Ocotea paranaensis e espécies supostamente relacionadas.

Table 1 - Morphological comparison of Ocotea paranaensis and presumably related species.

\begin{tabular}{lcccc}
\hline Características & Ocotea paranaensis & Ocotea lancifolia & Ocotea pulchella & Ocotea bicolor \\
\hline Ápice da folha & acuminado & agudo & obtuso a acuminado & acuminado \\
Pares nervuras secundárias & $4-6$ & $6-10$ & $4-6$ & $6-10$ \\
Domácias na folha & ausentes & ausentes & presentes & ausentes \\
Indumento da flor & tomentoso & pubérulo ou ausente & pubérulo & ausente \\
Forma do fruto & globoso & elipsóide & ovalado ou elipsóide & globoso ou elipsóide \\
Margem da cúpula do fruto & simples & dupla & simples & hexalobada \\
\hline
\end{tabular}

anteras em geral retangulares, mais longas que largas, filetes bem definidos, em geral mais curtos que as anteras, ovário piloso a glabro e fruto globoso a elíptico. Um caráter comum ao grupo é a presença de frutos com a margem dupla, o que não é observado nessa nova espécie.

\section{Agradecimentos}

Os autores agradecem à Fundação Araucária e ao Conselho Nacional de Desenvolvimento Científico e Tecnológico (CNPq) as bolsas de Iniciação Científica e de Mestrado concedidas a Marcelo L. Brotto e de Produtividade em Pesquisa a Armando C. Cervi e Élide P. Santos.

\section{Referências}

Almeida, F.F.M. de \& Carneiro, C.D.R. 1998. Origem e evolução da Serra do Mar. Revista Brasileira de Geociências 28: 135-150.

Assis, L.C.S. \& Mello-Silva, R. 2009. Three new species of Ocotea (Lauraceae) from Brazilian Atlantic forest. Rodriguésia 60: 641-649.

Baitello, J.B. 2001. Novas espécies de Lauraceae para a flora brasileira. Acta Botanica Brasilica 15: 445-450.
Brotto, M.L.; Santos, E.P. \& Baitello, J.B. 2009. Lauraceae no Morro dos Perdidos (Floresta Atlântica), Paraná, Brasil. Rodriguésia 60: 445-459.

IUCN. 2001. IUCN Red list categories and criteria: version 3.1. IUCN Species Survival Commission. IUCN, Gland and Cambridge. ii + 30pp. Disponível em <http://www.iucnredlist.org/static/categories_ criteria_3_1>. Acesso em 7 outubro 2009.

MMA - Ministério do Meio Ambiente. 2008. Instrução Normativa $N^{\circ} 6$ de 23/09/2008.

Quinet, A. 2008. Uma nova espécie de Ocotea (Lauraceae) para o estado do Espírito Santo, Brasil. Rodriguésia 59: 339-342.

Rohwer, J. G. 1986. Prodromus einer Monographie der Gattung Ocotea Aubl. (Lauraceae), sensu lato. Mitteilungen aus dem Institut fur Allgemeine Botanik Hamburg. 278p.

Rohwer, J. G. 1993. Lauraceae. In: Kubitzki, K.; Rohwer, J. G.; Bittrich, V. (eds.). The families and genera of vascular plants. Vol. 2. Springer-Verlag, Berlin. Pp. 366-391.

Thiers, B. 2009. [continuamente atualizado]. Index Herbariorum: A global directory of public herbaria and associated staff. New York Botanical Garden's Virtual Herbarium. Disponível em <http://sweetgum. nybg.org/ih/>. Acesso em 15 agosto 2009. 